Anas A Mohammad BDS, MSc (Assist Lect)

\section{Management of gagging patient during intra-oral posterior region radiography}

\author{
Department of Oral and Maxillofacial Surgery
}

College of Dentistry, University of Mosul

\begin{abstract}
The aim of this study is to determine the relation of gag reflex with sex of the patient and the region of the radiograph during intra-oral radiographic technique. The study also shows the difference in the management of gagger patient by the radiologist than the dental student as operator.

A sample of 115 students from College of Dentistry, University of Mosul; their ages 20-26 years were examined radiographically for their wisdom teeth condition.

The females show higher incidence of gag reflex than males and in the maxillary region than the mandibular one. The right side of the patient shows high percentage of gag reflex than the left side.

The results also reveal that the management of the radiologist to the gagger patient (by experience and several technical and instruction steps) shows successful results in resolving the gagging problem (96.2\%).
\end{abstract}

Key Words: Radiologist management, gag reflex, periapical radiography.

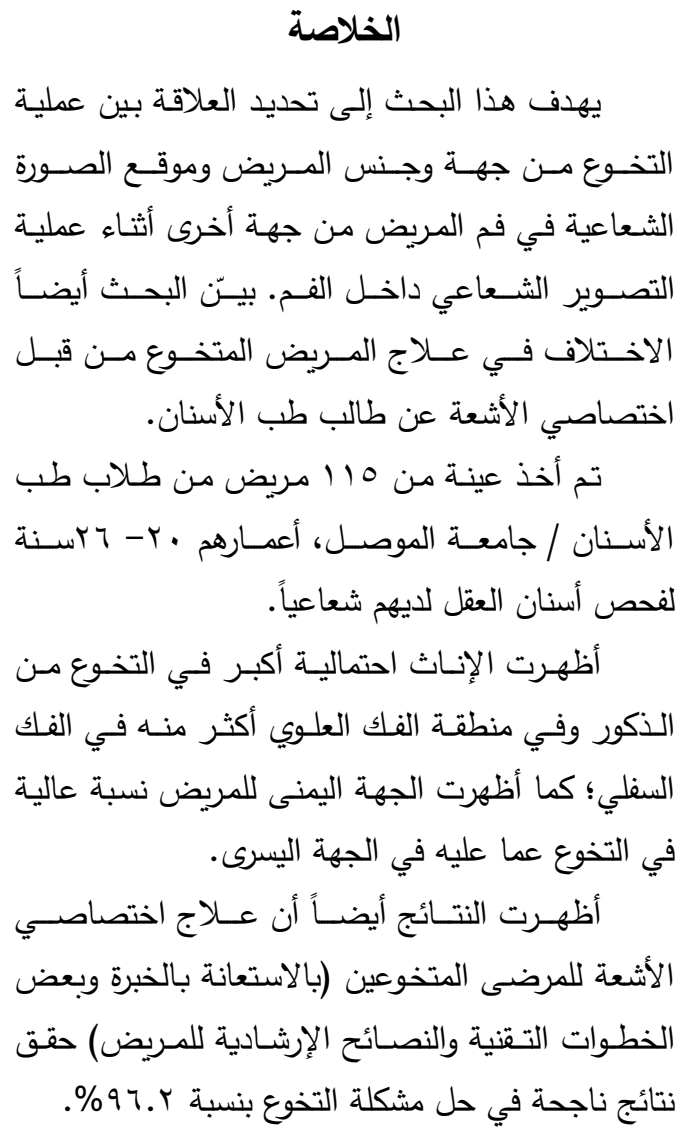

\section{INTRODUCTION}

Gagging is a reflex normally initiated by mechanical stimulation of the facial pillars, base of the tongue, palate and posterior pharyngeal walls. The reflex is protective in nature and can be initiated over several afferent pathways. ${ }^{(1,2)}$

The normal gag reflex is an adaptive, vital mechanism for survival controlled primarily by the parasympathetic division of the autonomic nervous system. ${ }^{(3)}$
The gag reflex is common to all people, but is more active in some than in others. Intra-oral films are placed in oral areas specifically related to the initiation of this reflex. The best method of controlling gagging is through technical expertise and authoritarianism tempered with compassion. $^{(4)}$

The posterior region is the area most difficult for the gagging patient to tolerate dental radiography. ${ }^{(5,6)}$ The operator must 
be able to preset the patient and the machine, use quick angulation procedures. ${ }^{(5)}$

The first and probably the best counteractant to the gag reflex is a calm, reassuring voice. Through this type of communication the patient will rapidly develop confidence in you, which will allay his fear and apprehension proportionately. ${ }^{(7)}$

Several technical instruction points and steps that discussed by more than researcher were illustrated later in the materials and methods of this study.

Further suggested methods for treatment of gag reflex include anesthetizing the soft palate, ${ }^{(8,9)}$ or use of various drugs such as sedatives, antihistamines, antinauseants and parasympatholytics. ${ }^{(8-10)}$ Several authors were advocated hypnosis. ${ }^{(10-12)}$ These anesthetics and premedications have drawbacks and side effects and may make the patient apprehensive. ${ }^{(13)}$

Xianyun suggested pressing two Chinese caves, or acupuncture caves, as an alternative to reduce the gag reflex. ${ }^{(14)}$ Others found success in controlling patient's gag reflex using ear acupuncture. ${ }^{(15)}$ Here, some minor bruising or bleeding may occur, which is the result of a needle hitting small blood vessels. ${ }^{(16,17)}$

Friedman et al. suggested that instructing the patient to extend their tongue so salt can be placed on the tip of the tongue would reduce the gag reflex. ${ }^{(6)}$

In this study, there is concentration on the difference between dental students and the senior radiologist in the management of the gagger patient during intra-oral radiographic technique for the wisdom region. In addition, the present study determines the relationship of the gag reflex with sex of the patient and site of the radiograph have been taken inside the patient's mouth.

\section{MATERIALS AND METHODS}

This research was carried out in the Department of Oral and Maxillofacial Surgery / Maxillofacial Radiology Section at College of Dentistry in Mosul University.
The sample of the study represented by 115 Mosul dental students (59 males and 56 females); their ages 20-26 years, for examining their impacted wisdom teeth condition. Bisecting angle technique was used in this study.

The following equipment were used:

1) Dental $x$-ray machine

(Trophy-France).

2) Periapical film size (2)

adult type.

Each patient was radiographed four times by dental student as operator (fourth class students). When the patient start to gag, the student operator instructed to ask for the radiologist assistance (the radiologist here is the researcher of this study). The management of the senior radiologist to the patient summarized by several instruction points or steps oriented according to the severity of the gag condition from simple to difficult one.

Instructions and Technical Steps

1) The first and probably best counteractant to the gag reflex is a calm, reassuring voice in which through this type of positive gentle communication, the patient may rapidly develop con-fidence in the operator which will allay his fear and apprehension pro-portionately. ${ }^{(7)}$

2) Never ask the patient "Are you a gagger?", because this will set a stage for the gag reflex. ${ }^{(7)}$

3) Ask the patient to swallow deeply just before opening the mouth and relax including tongue relaxation during film placement. This point especially for the mandibular periapical radio-graph. ${ }^{(18)}$ Place the film at a greater angle to the tooth, allowing the infer-ior edge to be placed deep underneath the tongue. ${ }^{(7)}$

4) Never mention the tongue. Don't ask the patient to relax the tongue, because this usually makes patient more cons-cious of it and precipitates involun-tary movements. ${ }^{(18)}$

5) Ask the patient to breath deeply from his nose and never breath through his mouth. ${ }^{(4,5,18)}$

6) Some time ask the patient to stop brea-thing during film placement and 
exp-osure after taking a deep inspiration (here required rapid exposure and film placement technique). ${ }^{(4,18)}$

7) Carry the film into the mouth parallel to the occlusal plane and when it is at desired area, rotate it with a decisive motion bringing it into contact with the palate or in the floor of the mouth (sliding it along the palate or tongue is likely to stimulate the gag reflex). ${ }^{(7,18)}$

8) The placement of the film inside the patient's mouth should be as short as possible and this can be carried out by fast technical experience and adjusting the $\mathrm{x}$-ray tube angulation and point of entry nearly the suspected exact position before insertion of the $\mathrm{x}$-ray film inside the patient's mouth. ${ }^{(5,18)}$

9) Some time ask the patient a question and tell him that you need the answer after exposure time, or ask the patient to observe and concentrate on a spot on the wall or ask the patient to keep a foot or arm suspended during film placement and exposure. This is to make the patient shift his attention from the film in his mouth. ${ }^{(18)}$

\section{RESULTS}

Data were collected from 115 patients, classified into three groups according to their ages as shown in the tables.

Generally, a 102 periapical radiographs revealed gag reflex from 408 total radiographs, which gave exactly $25 \%$ of gag reflex according to the number of the radiographs have been taken; whereas 53 patients show gag reflex in one or more radiographs from 115 patients creating about $46 \%$ according to the number of the patients have been radiographed.

The results of gag reflex incidence and distribution among patients age, sex and the region of the radiograph obtained by dental students as operators were summarized in Tables (1, 2, 3, 4 and 5).

Table (1) represents the variation in gag reflex between males and females, shows that gag reflex is more prevalent in the females than males with significant value $(Z-$ test $=2.312$ at 0.05 level of significance).

Table (1): Sex differences for the gag reflex

\begin{tabular}{cccc}
\hline $\begin{array}{c}\text { Patient's } \\
\text { Age } \\
\text { (Years) }\end{array}$ & $\begin{array}{c}\text { Males } \\
\text { (No.) }\end{array}$ & $\begin{array}{c}\text { Females } \\
\text { (No.) }\end{array}$ & $\begin{array}{c}\text { Total } \\
\text { (No.) }\end{array}$ \\
\hline $\mathbf{2 0}-\mathbf{2 1}$ & 9 & 11 & 20 \\
$\mathbf{2 2}-\mathbf{2 3}$ & 10 & 18 & 28 \\
$\mathbf{2 4}-\mathbf{2 6}$ & 2 & 3 & 5 \\
\hline Total & 21 & 32 & 53 \\
\hline
\end{tabular}

Tables (2) and (3) show the variation of gag reflex incidence between the two sides of the jaws respectively, both Tables show higher significant difference for the gag reflex incidence at the right side than the left one. Table (2) shows Z-test value $=$ 3.935 at 0.05 level of significance in accordance to the number of patient sample; whereas Table (3) shows Z-test value $=4.231$ at 0.05 level of significance in accordance to the number of the periapical radiographs where gag reflex have been observed.

Table (2): Variation of gag reflex incidence between two sides of the jaws in accordance to the number of patients

\begin{tabular}{cccc}
\hline $\begin{array}{c}\text { Patient's } \\
\text { Age } \\
\text { (Years) }\end{array}$ & $\begin{array}{c}\text { Right } \\
\text { Side }\end{array}$ & $\begin{array}{c}\text { Left } \\
\text { Side }\end{array}$ & $\begin{array}{c}\text { Total } \\
\text { No. of } \\
\text { Patients }\end{array}$ \\
\hline $\mathbf{2 0}-\mathbf{2 1}$ & 20 & 6 & 26 \\
$\mathbf{2 2}-\mathbf{2 3}$ & 28 & 15 & 43 \\
$\mathbf{2 4}-\mathbf{2 6}$ & 5 & 4 & 9 \\
\hline Total & 53 & 25 & 78 \\
\hline
\end{tabular}

Table (3): Variation of gag reflex incidence between two sides of the jaws in accordance to the number of radiographs

\begin{tabular}{cccc}
\hline $\begin{array}{c}\text { Patient's } \\
\text { Age } \\
\text { (Years) }\end{array}$ & $\begin{array}{c}\text { Right } \\
\text { Side }\end{array}$ & $\begin{array}{c}\text { Left } \\
\text { Side }\end{array}$ & $\begin{array}{c}\text { Total No. of } \\
\text { Radiographs }\end{array}$ \\
\hline $\mathbf{2 0}-\mathbf{2 1}$ & 27 & 7 & 34 \\
$\mathbf{2 2}-\mathbf{2 3}$ & 35 & 19 & 54 \\
\hline
\end{tabular}




\begin{tabular}{cccc}
\hline $\mathbf{2 4 - 2 6}$ & 8 & 6 & 14 \\
\hline Total & 70 & 32 & 102 \\
\hline
\end{tabular}

Tables (4) and (5) show the difference of gag reflex incidence between the maxillary and mandibular wisdom areas respectively. Both Tables show higher prevalence of gag reflex in the maxillary region than that of the mandibular one, but in low degree, with no significant diff-erence at $p<0.05$ level. Table (4) shows $\mathrm{Z}$-test value $=0.426$ at 0.05 level of sign-ificance in accordance to the number of patient sample; whereas Table (5) shows $\mathrm{Z}$-test value $=0.436$ at 0.05 level of significance in accordance to the number of periapical radiographs where gag reflex have been observed.

Table (4): Incidence of gag reflex between the maxillary and mandibular wisdom region

in accordance to the number of patients

\begin{tabular}{cccc}
\hline $\begin{array}{c}\text { Patient's } \\
\text { Age } \\
\text { (Years) }\end{array}$ & Maxillary Mandibular & $\begin{array}{c}\text { Total } \\
\text { No. of } \\
\text { Patients }\end{array}$ \\
\hline $\mathbf{2 0}-\mathbf{2 1}$ & 17 & 12 & 29 \\
$\mathbf{2 2}-\mathbf{2 3}$ & 17 & 19 & 36 \\
$\mathbf{2 4}-\mathbf{2 6}$ & 4 & 4 & 8 \\
\hline Total & 38 & 35 & 73 \\
\hline
\end{tabular}

Table (5): Incidence of gag reflex between the maxillary and mandibular wisdom region in accordance to the number of radiographs

\begin{tabular}{cccc}
\hline $\begin{array}{c}\text { Patient's } \\
\text { Age } \\
\text { (Years) }\end{array}$ & Maxillary Mandibular & $\begin{array}{c}\text { Total No. of } \\
\text { Radiographs }\end{array}$ \\
\hline $\mathbf{2 0}-\mathbf{2 1}$ & 20 & 14 & 34 \\
$\mathbf{2 2}-\mathbf{2 3}$ & 26 & 28 & 54 \\
$\mathbf{2 4}-\mathbf{2 6}$ & 7 & 7 & 14 \\
\hline Total & 53 & 49 & 102 \\
\hline
\end{tabular}

The above results illustrated in Tables $(1,2,3,4$, and 5$)$ were obtained by dental students experience as operators (fourth class students). All dental students operators that failed to obtain successful exposure without gag reflex from the patient were asked for supervisor assis- tance (the senior radiologist was the researcher of this research).

The management of radiologist was in accordance to the instruction points illustrated in the materials and methods. Fifty one patients from 53 gagger patients were respond to the management (96.2\%). The non-respond two patients were referred to the panoramic radiography.

\section{DISCUSSION}

Generally, the incidence of gag reflex in this study shows high percentage which is about $25 \%$ from the total number of radiographs have been taken; whereas it is about $46 \%$ from the total number of patients have been radiographed. This was attributed to the poor technical experience of the dental students as operators.

The incidence of gag reflex in the females is higher than that of the males with significant sex difference at $p<0.05$ as shown in Table (1). This difference may be attributed to two facts. The first one is that females have relatively small jaws than males which may interfere with film placement. The second fact is the suggestion that females being psychologically more sensitive and apprehensive than males which may exaggerate the gag reflex condition. This finding and attribution was in agreement with Krol findings, who stated that "Such gagging is usually psychogenic in origin and can result from excessive fear, apprehension or anxiety". ${ }^{19)}$ Also, this finding was in agreement with O'Brien study, who reported that "Gagger patient may appear calm and stoic, but the truth is that they are actually quite nervous and fearful, which lowers the threshold to a gag reflex". (7)

The incidence of gag reflex at the right side (maxillary and mandibular one) was higher than that of the left side with great significant differences at $p<0.05$ as shown very clearly in Tables (2) and (3). The difference may be due to the fact that the student operator have only one approach to the patient during film placement and beam adjustment which is standing of the operator at right side of the 
patient (standing of the operator at left side of the patient may interfere with the movement of the arm of the $\mathrm{x}$-ray machine which holds on the wall at left side of the patient). Under such circumstance, the right cheek of the patient may block the vision of the operator to the right examined area, which may result in student operator pushing the film backward distally inside patient mouth touching the soft palate, dorsum of the tongue and pharyngeal wall creating the gag reflex without attention.

Tables (4) and (5) show that the incidence of gag reflex in the maxillary wisdom region is slightly higher than that of the mandibular one with no significant difference at $p<0.05$. This result is in agreement with the finding of MansonHing, who stated that "The maxillary posterior region is the area most difficult for the gagging patient to tolerate dental radiography". (5) The high incidence of gag reflex in the mandibular region was attributed to the poor experience of student in dealing with the tongue during film placement.

The management of the gagger patient by radiologist with the use of the instruction and technical points illustrated in the materials and methods was in accordance with the several reported instructions by researchers in this field. ${ }^{(4,5,7,18)}$
The successive results obtained in this study for management of the gag reflex by the radiologist was previously discussed by Wuehrmann and Manson-Hing, who stated that "The best method of controlling gagging is through technical expertise and authoritarianism tempered with compassion. The creation of patient confidence through demonstrated ability and development of a non-permissive approach in interpersonal relationships greatly minimizes gagging. This can be observed readily in a dental school clinic situation. A student who has trouble with a gagging patient is often surprised at the ease with which the instructor obtains patient cooperation. The operator must know what he is doing and must do it expeditiously". ${ }^{(4)}$

\section{CONCLUSION}

From this study, it was concluded that the females were more susceptible to gag reflex than males. The right side had higher prevalence to gag reflex than the left one and the maxillary region than the mandibular one but in low degree. However, most gagging can be controlled by creation of patient's confidence with high demonstration ability from the operator.

\section{REFERENCES}

1. Bradley RM. Basic Oral Physiology. $1^{\text {st }}$ ed. Year Book Medical Pub, Inc. 1981; p: 195.

2. $\quad$ Roth GI, Calmes R. Oral Biology. $1^{\text {st }}$ ed. CV Mosby Co. 1981; p: 69.

3. Murphy WM. A clinical survey of gagging patients. J Prosthet Dent. 1979; 42: 145148.

4. Wuehrmann AH, Manson-Hing LR. Dental Radiology. $5^{\text {th }}$ ed. CV Mosby Co. 1981; p: 218.

5. Manson-Hing LR. Fundamentals of Dental Radiology. $1^{\text {st }}$ ed. Lea \& Febiger Co. 1979; Pp: 146-147.

6. Friedman MH, Weintraub MI. Temporary elimination of gag reflex for dental procedures. J Prosthet Dent. 1995; 73: 319.

7. O'Brien RC. Dental Radiology. An Introduction for Dental Hygienists and Assistants. $4^{\text {th }}$ ed. WB Saunders Co. 1982; Pp: 147-148. 
8. Watt DM, MacGregor AR. Designing Complete Dentures. $2^{\text {nd }}$ ed. Bristol. IOP Publishing, Ltd. 1986; p: 155. Cited by: Ansari IH. Management for maxillary removable partial denture patients who gag. J Prosthet Dent. 1994; 72: 448.

9. Means CR, Flenniken IE. Gagging: A problem in prosthetic dentistry. J Prosthet Dent. 1970; 23: 614-620.

10. Schole ML. Management of the gagging patient. J Prosthet Dent. 1959; 9: 578-583.

11. Kramer RB, Braham RL. The management of chronic hysterical gagger. J Dent Child. 1977; 44: 111-116.

12. Ament P. Removal of gagging: A response to variable behavior patterns. Int J Clin Exp Hypn. 1970; 19: 1-9.

13. Ansari IH. Management for maxillary removable partial denture patients who gag. $J$ Prosthet Dent. 1994; 72: 448.

14. Xianyun R. Making an impression of a maxillary edentulous patient with gag reflex by pressing caves. J Prosthet Dent. 1997; 78: 533.

15. Today's News. Acupuncture can control gag reflex during dental treatment. June, 25, 2001.

16. Rusy LM, Hoffman GM, Weisman SJ. Electroacupuncture prophylaxis of postoperative nausea and vomiting following pediatric tonsillectomy with or without adenoidectomy. Anesthesiol. 2002; 96(2): 300-305.

17. Irnich D, Winklmeier S, Beyer A, Peter K. Electric stimulation acupuncture in peripheral neuropathic pain syndromes. Clinical pilot study on analgesic effectiveness. Schemeiz. 2002; 16(2): 114-120.

18. Goaz PW, White SC. Oral Radiology. Principles and Interpretation. $1^{\text {st }}$ ed. CV Mosby Co. 1982; Pp: 242-243.

19. Krol AJ. A new approach to the gagging problem. J Prosthet Dent. 1963; 13: 611616.

Received: $10 / 12 / 2002$

Accepted for Publication: 19/1/2003 